\title{
Toward a New Conceptual Model: Integrating the Social Change Model of Leadership Development and Tinto's Model of Student Persistence
}

\author{
Andrew French \\ Ph.D. Student \\ Higher Education \\ Loyola University Chicago
}

\begin{abstract}
This paper contributes a new conceptual framework for understanding undergraduate student persistence. The social change model of leadership development (SCM), with its emphasis on helping students develop leadership capabilities and encouraging them to work for the common good, has been chosen for integration with Vincent Tinto's 1975 model of student persistence, which is widely considered a landmark framework in retention and persistence scholarship. In consideration of the ways in which the SCM and the Tinto model have the potential to complement each other and address each other's shortcomings, this paper proposes an incorporation of the frameworks toward the creation of a new structure for conceptualizing how institutions approach student persistence, and it is thus useful for a wide range of stakeholders in the field.
\end{abstract}

\section{Introduction}

Theories, frameworks, and perspectives that inform the shaping of new educational practices need not be disconnected. Indeed, with the inherent emphasis theoretical integration places on absorbing concepts and joining together propositions from different theories, creating and putting into practice integrated conceptual frameworks can be valuable to the change process undertaken by organizations from numerous fields (Thornberry, 1989). Integrated conceptual frameworks can be particularly useful for higher education because the connectedness that exists among the different areas of the academe makes blended theoretical approaches useful for strategizing and considering new ideas for implementation. Integrated conceptual frameworks not only provide unique spaces to connect theories from different disciplines, but they can help address shortcomings of prevailing theories and establish more inclusive and direct approaches to aid in the improvement of existing theory and practice. Finally, integrating theories can have the benefit of creating a reciprocal effect, whereby the new framework provides a construct for components of the integrated theories to complement each other.

There are numerous steps necessary to the process of creating a new integrated conceptual framework. First, it is important to articulate a theoretical framework that will guide the creative process and serve as the basis for explaining relationships and making connections between core tenets of the framework. It is also necessary to provide 
a rationale for the selection of the theories being integrated, offer an explanation for why the integration of these theories will be useful for both theory and practice, and set forth a synthesis, analysis, deconstruction, and reconstruction of the selected theories.

Particularly important to this process is the reconstruction element. Not only does reconstruction involve addressing shortcomings, but by providing a roadmap for possibilities, reconstruction serves as the lynchpin for establishing the foundation for the new single integrated framework (Dugan, 2017). Finally, a discussion of how the new conceptual framework specifically and meaningfully integrates the selected theories and how the new model will have an impact on theory and practice will be important.

\section{Theoretical Framework}

In exploring and unpacking the concept of student learning and its potential relationship to persistence, Wolniak, Mayhew, and Engberg (2012) relied upon the National Council for Liberal Education and America's Promise report, College Learning for the New Global Century, to highlight the importance of socially responsible leadership as an important dimension to learning outcomes (Tyree, 1998). Specifically, in examining students' persistence between the first- and second-year of college, Wolniak, et al. (2012) established that those who acquired key socially responsible leadership capabilities were more likely to enroll for their second year of college. Moreover, in examining numerous factors related to learning constructs and academic and social integration, their study indicates that socially responsible leadership and grade point average were the only factors to have a statistically significant relationship with persistence. As the Wolniak, et al., (2012) work suggests, when students, particularly first-year students, participate in campus leadership opportunities, those experiences can be valuable to shaping a student's feeling of engagement and involvement, which plays a role in establishing an important relationship between socially responsible leadership and persistence. In establishing connections between leadership participation and persistence, the Wolniak, et al., (2012) study serves as an important theoretical framework for this paper.

\section{Selected Theories and Justification}

For the purposes of this project, I have chosen to integrate the social change model of leadership development (SCM) and Vincent Tinto's model of student persistence, each of which will be discussed in greater detail in the forthcoming synthesis section. I have chosen these theories because I believe their integration has the potential to be uniquely beneficial to thinking more deeply about the value of applying the SCM in an effort to address a specific issue in higher education, in this case undergraduate student persistence. Integrating these theories also has the potential to challenge underlying assumptions about the study of persistence, which is among the most important challenges facing modern college and university administrators. This challenge includes not only understanding the rates at which students persist or not, but the reasons for student persistence decisions and the kinds of high-impact practices in which institutions can engage in working toward solutions. It is incumbent upon institutions to prioritize persistence, and the SCM is a useful instrument to do so. 
The integration of the SCM and Tinto theories has the potential to enhance the ways in which undergraduate student persistence is understood in relation to leadership. As the SCM focuses on collaborative and inclusive leadership, integrating it with the Tinto model has the potential to offer a roadmap for how to re-conceptualize and create a more inclusive approach. Additionally, as will be discussed here, integrating these theories has numerous equity and social justice implications. Finally, this new conceptual framework, which I have titled Improving Persistence though Social Change Leadership (IPSCL), also has the potential to make an important contribution to the field of leadership theory and application by providing a tool to create new pedagogies and to aid in the integration of theory and practice (Enns \& Sinacore, 2005).

\section{Synthesis of the Selected Theories}

Social Change Model of Leadership Development. First published in 1996 by the Higher Education Research Institute, the SCM is a widely used leadership model that has been particularly useful as a framework for defining and promoting leadership development among undergraduate college students (Owen, 2012). While other models that challenge institutions to use leadership frameworks were designed for corporate environments, it is this specific and intentional focus on the undergraduate student that makes the SCM unique (Wagner, 1996). The SCM, which integrates existing leadership development concepts, outlines a deliberate and collaborative process for leadership training rooted in values and service in which participants work toward creating positive change for the common good (Dugan, Kodama, Correia, \& Associates, 2013; HERI, 1996; Humphreys, 2011; Kezar, 2010).

Different from traditional notions of leadership that focus on prototypes of the gallant leader who independently creates transformational change (Alvesson \& Spicer, 2014; Liu \& Baker, 2014), the SCM, with its emphasis on collaboration, suggests that all people can be leaders in the positive change process (Kezar, 2010). At its foundation, the SCM is a model designed with the idea of encouraging and providing guidelines to people who want to make positive changes to their organizations. As the SCM outlines, it is this emphasis on positive social change that should be the fundamental goal of leadership (Owen, 2012). The positive social change resulting from successful implementation of the SCM is values-based, and it encourages students to organize and to collaborate to promote equity, social justice, empowerment, and citizenship within the community (Cilente, 2009; Dugan, et al., 2013; Owen, 2012).

The SCM focuses on leadership as a process (Owen, 2012). Pivotal to this process are the model's leadership spheres through the perspective of the individual, group, and society, and the interrelationship between them (Dugan et al., 2013; Komives \& Wagner, 2012). Also important to the SCM is the commitment to the seven critical values: consciousness of self, congruence, commitment, collaboration, common purpose, controversy with civility, and citizenship (Dugan, et al., 2013; HERI, 1996; Kezar, 2010). Change is the eighth value, and is meant to be the principal goal in the process (Owen, 2012). 
Consciousness of self, congruence, and commitment are attached to the individual values component, where the main focus is on understanding the personal qualities sought after by those who participate in leadership development and on enhancing individuals' ability to understand themselves so that they can meaningfully involve others in a collaborative and creative process (Dugan, et al. 2013; Dugan, 2006; HERI, 1996). Collaboration, common purpose, and controversy with civility attach to the group values component where the main focus is on how collaborative leadership can encourage not only individual actors, but also create broader positive social change (Dugan, et al. 2013; HERI, 1996). Finally, citizenship connects to the community/society component where the emphasis is on the kinds of positive social outcomes sought after by leadership development (HERI, 1996; Humphreys, 2011). Additionally, as Dugan et al., (2013) suggest, the sequential nature of the leadership learning process is an important part of understanding the SCM. In this sequential process, the individual impacts the group, which then impacts the community or society (Dugan, et al., 2013).

It is also important to note, especially for the purposes of this project, that the SCM is adaptable and open to revision by those implementing it (HERI, 1996). Further, it is understood that those using the SCM may incorporate only those components they find to be most useful to their leadership development needs (HERI, 1996). The malleability of the model contributes to its usefulness into an integrated framework.

Tinto's Model of Student Persistence. Vincent Tinto first outlined his model explaining motivations for undergraduate student dropout rates in his 1975 work. Even as the model has evolved over the years, the core original framework has remained one of the most important and formative in the modern study of undergraduate student persistence and retention (Berger \& Lyon, 2005; Braxton, Sullivan, \& Johnson, 1997; Kuh, Kinzie, Buckley, Bridges, \& Hayek, 2006). Indeed, the Tinto model has in many ways gained definitive standing in the field and has sparked both keen interest and new research streams about why students leave college and the roles institutions can play in reversing the trends (Braxton, et al., 1997).

In short, Tinto's (1975) original model directly connected the environments of colleges and universities with rates of student retention, specifically suggesting that college students who are best able to immerse themselves into the new institutional context are more likely to persist in their studies and thrive socially in the environment than those who are not (Tinto, 1975). Parenthetically, Tinto focuses most extensively on the first-year experience, because that is when the greatest number of students will make their persistence decisions (Elkins, Braxton, \& James, 2000; Tinto, 1987).

Tinto's model relies on two core principles: academic integration and social integration, which Tinto suggests have an interrelated and reciprocal effect with respect to student persistence. As to academic integration, Tinto measures this by student grade performance and intellectual development, though he emphasizes that grades, as the easier to define and more tangible form of validation from the academic system, represent the more important acknowledgement from the institution that the student has 
participated (Tinto, 1975). As a consequence, for the student, his academic performance, measured by grades, is most reflective of how effectively he has adopted the institution's academic norms and integrated academically (Tinto, 1975). This, in turn, becomes important to the student's persistence decision (Tinto, 1975).

Academic performance plays an important role, but Tinto (1975) suggests that social integration is just as meaningful to student satisfaction and, ultimately, to persistence decisions. Tinto (1975) explains that integration into the social spheres of the campus in the way of informal peer groups, extracurricular opportunities, and interaction with faculty members and administrators, leads to students feeling rewarded and experiencing a sense of affirmation, which is important to how they evaluate the value and opportunity cost of attending college. This, consequently, impacts a student's commitment to his education and to the institution (Tinto, 1975). Taken collectively, these elements of social integration play a role in whether that student will stay in college (Tinto, 1975).

By Tinto's own admission, the original 1975 model is, in hindsight, quite limited in its complexity and breadth (Tinto, 2007). For example, the original model focused almost entirely on residential institutions and students from demographic majority backgrounds. As such, it does not take into account other institution types like community colleges, nor does it address the experiences of students who are diverse with respect to gender, race, ethnicity, income, sexual orientation, first-generation status, or socioeconomic status. Recognizing these shortcomings, Tinto has made numerous additions and modifications to the original 1975 model. In an important revision, Tinto (1993) identified new groups of students who, because of their unique backgrounds, are deserving of special consideration from the academe and could require specific interventions from the institution. These groups included African American students, low-income students, and other "non-traditional" students including adults and transfers (Tinto, 1993).

Related to the inclusion of these groups into Tinto's amended framework is one of the most controversial revisions, and one that will be a focal point of my deconstruction: the concept of stages of passage in the college student career (Tinto, 1988). Relying on the work of Dutch anthropologist Arnold Van Gennep, who suggested that the movement of people from youth to adulthood centers around the phases of separation, transition, and incorporation, Tinto (1988) suggested that students entering college must separate themselves from their precollege contexts (e.g., high school peers, families, and community relationships). They must then begin the transition process, meaning intentionally adopting the values and norms of the new community (Tinto, 1988). Finally, in the incorporation phase, students must fully integrate into the community of the institution by gaining membership in the college's social environment (Tinto, 1988).

Other revisions and amendments to Tinto's original model have included goal commitment as a variable, the importance of quality academic advising, the availability of accessible academic, personal, and social support services, increased prospects for meaningful faculty-student interaction through undergraduate research programs, and the 
institutional elimination of cultural barriers that serve as roadblocks to students integrating socially into the campus community (Kuh, et al., 2006; Tinto, 1999; Tinto, 2004; Tinto, 2007). Other significant shifts in Tinto's recent revisions have been the focus on academic integration and the important role faculty members can play in student engagement and the decreasing relevance to administrators of student entry characteristics because of the inability to control for past experiences (Tinto, 2007).

Certainly there are multiple models of retention that are more contemporary and could be used in making connections between a leadership framework and persistence, but as Tinto's is among the most cited and important, I have use that as a frame of reference.

\section{Deconstruction of the Selected Models}

The Tinto Model. While Tinto's model has generated wide support by numerous scholars since its inception and has shaped how researchers and practitioners understand undergraduate college student retention, it has also been extensively scrutinized for its theoretical and practical limitations (Swail, 2004). Using a critical lens, the areas in which there are perhaps the greatest opportunities for deconstruction are with Tinto's position on social integration and with the lack of application of his model to nonmajority students. While Tinto suggests that a student's ability to socially integrate into the college community is aligned with her feelings of connection to the institution and eventual success, a critical perspective would suggest that, since the original Tinto (1975) model does not consider important concepts like social location, and instead largely takes into account only the experiences of majority students who already possess or have access to the kinds of cultural norms, rules, and customs that are aligned with the dominant norms, rules, and customs of the institution, there is a foundational limitation to Tinto's scope and analysis (Berger \& Melaney, 2003; Dugan, 2017; Kuh, et al., 2006; Museus, 2014). This point gives weight to ideological critiques which suggest that, in failing to consider diverse students and their experiences, Tinto's model, though unknowingly, may have contributed to the perpetuation of a system of cultural bias (Museus, 2014), and thus reflects the kind of willful blindness described by Dugan (2017).

For example, Tinto's (1975) original model does not consider the experiences of transfer students, many of whom have widely diverse family and economic contexts than the "typical" majority student. These and other factors can lead to a "transfer shock" experience, which can have a significant impact on the persistence decisions of these students (Laanan, 2001). The situation is similar for first-generation students who are at a disadvantage without the kinds of social experiences valued by a majority of continuing-generation students, making it more difficult for them to develop the social capital necessary to feel fully engaged with the institution (Housel \& Harvey, 2009). According to the self-determination critique offered by Museus (2014), Tinto's model places the responsibility to feel engaged and gain social capital exclusively on the students, without recognizing the important role institutions play in guiding these students toward success. 
Using other critical tools, Tinto's model is also open to deconstruction through critical ethnography. Focusing as he does on the fit between the student and the institution, the Tinto model can be viewed as culturally biased because of its basic assumptions about what is needed for a student to persist in college (Kuh, et al., 2006). Research has shown that students from racially and ethnically diverse backgrounds who, because of differences in the levels of social capital they possess, may encounter roadblocks on their way to collegiate social integration (Berger \& Melaney, 2003; Kenny $\&$ Stryker, 1996). This is one of many examples of nuance in understanding the needs of undergraduate students, and absent such elements, the Tinto model is limited.

Tinto's $(1975,1987)$ model also suggests that a student's ability to socially integrate is dependent on the ability to separate from the former group (e.g., high school friends) and adopt the values and norms of the new college group. As such, Tinto establishes a link between student persistence and the relationships that students are able to form once in college. However, Tinto fails to take into account how the inherently unequal power dynamics that often exist in many institutional contexts can make such integration unrealistic for students from diverse backgrounds (Metz, 2004). For example, Tierney (1992a, 1992b) suggests that there are important and distinct contextual elements to consider with Native Americans college students, whose transition to higher education often represents a significant cultural disruption. In his (1992b) case study of such students, Tierney highlights a perception among student participants that there exists a "culture of power" in higher education. Additionally, insight from the student participants clearly underscore that the Native American college experience is vastly different from the majority experience assumed by the original Tinto model (Tierney, 1992b). Especially using the lens of cultural ethnography, the question, then, becomes whether the kind of social conformity and assimilation that Tinto suggests as being all but an imperative is really necessary or holds any value whatsoever (Kuh, et al., 2006; Tierney, 1992a). Thinking about the cultural tensions, this element of Tinto represents an important shortcoming.

Finally, by focusing almost exclusively on majority students, Tinto's model does not take into account various social-psychological explanations for student retention that are especially relevant to underrepresented students. In their study, Bennett and Okinaka (1990) found that some underrepresented minority students have transitional encounters to college that can actually resemble traumatic experiences. Additionally, in their study focusing on underrepresented first-year students, Smedley, Myers, and Harrell (1993) found that students from diverse racial and ethnic backgrounds experience levels of psychological distress not experienced by majority students. These minority status stresses are an important consideration in understanding the potential pitfalls in the underrepresented student adjustment experience (Smedley, et al., 1993).

First-generation students, who are also excluded from the original Tinto model, experience similar social-psychological effects. In their study, Richardson and Skinner (1992) concluded that first-generation college students often disproportionately experience feelings of cultural alienation, isolation, and disconnection as they transition 
into college. First-generation students often perceive a lack of family support and a lack of encouragement from their friends as they transition into college and as they struggle with their persistence decisions (Donatelli, 2010; Terenzini, Springer, Yaeger, Pascarella, \& Nora, 1996). Some first-generation students report that family members actively discourage them from attending college, and that they experience problems creating friendships with college peers and finding balance between their academic and social expectations (Engle, Bermeo, \& O'Brien, 2006). Many of these students also develop strained relationships with precollege family and childhood friends, as it is perceived that the students are pulling away from their previous relationships (Engle, et al., 2006).

This is a much different scenario than occurs with many continuing-generation students. While some first-generation students see college as a pivotal point of disconnection in their lives and in the lives of their families, continuing-generation students view college as a logical continuation of their academic careers (Engle, 2007). For these continuing-generation students, college is an expectation that has been cultivated and nurtured by their families and reinforced by peer groups (Engle, 2007). This expectation informs not only their levels of academic preparation, but also how confident continuing-generation students are in their ability to effectively navigate and succeed in the college environment (Engle, 2007). The research clearly suggests that the social-psychological effects of transitioning into college are significant for many nonmajority, transfer, and first-generation students. Tinto's exclusion of these students from his original model represents not only an important shortcoming, but by effectively normalizing an existing social order, it is fair to criticize the model for being, albeit unintentionally, a hegemonic tool (Dugan, 2017).

In neglecting to incorporate diversity and related social-psychological elements into his original model, Tinto also fails to address the concepts of stereotype threat and social comparison as factors critical to student persistence decisions. Tinto's model accurately demonstrates that students arrive at college with widely different backgrounds and widely different ranges of precollege academic preparation, and these achieved characteristics and skill differences can have an impact on how college students view their ability to perform and to be successful in their coursework. While students from advantaged backgrounds may feel well-prepared for the challenges of higher education, those from backgrounds in which less social capital is acquired may experience feelings of inadequacy and intimidation in the college environment, and some experience feelings of isolation by the mere perception that negative stereotypes might exist (Born, Revelle, \& Pinto, 2002; Micari \& Drane, 2011). This stereotype threat may cause some students to view themselves as less skilled or less able to perform on a high level academically than their peers (Micari \& Drane, 2011).

Finally, and relating to practice, a shortcoming of the Tinto model is that it does not provide ideas for a specific roadmap for the creation of an effective institutional response to undergraduate student persistence. Tinto $(1997,2007)$ argues for the importance of institutional support programs geared toward improving levels of integration and, in turn, persistence. But what is missing from Tinto's outline is a broader and more integrated institutional approach reflective of the intentional inclusion 
of theoretical frameworks. Interestingly, this limitation is acknowledged by Tinto (2007) in which he suggests the need for a new model of institutional action that reflects multiple levels of understanding and which connects institutional policies, programs, and practices geared toward improving retention.

Social Change Model of Leadership Development. In comparison to the Tinto model, the SCM has not been deconstructed as frequently in academic literature. However, there are some important opportunities for deconstruction of the theory to consider, especially related to the concept of citizenship. Applying a critical lens to this aspect of the model, it does not address how and why people engage in social change activities motivationally, nor does it address issues related to the multiple conceptions of citizenship. This is not to say that the concept is left undefined. The model does outline the significance of active participation in the shared goal of change for the common good and the importance of interdependence and the responsibility of each participant to help further these objectives (HERI, 1996). The citizenship element of the SCM is democratic, meaning that it encourages participation by all interested in affecting change. Absent from the model is a hierarchical paradigm, further illustrating the idea that all participants have the space to become leaders. From this broad scope, however, emerge some important questions about what it means to be a good citizen at every level in addition to power considerations. Regarding the latter, the SCM carries with it potential for the kind of flow of power issues addressed by Dugan (2017) relating to the perception among non-participants that SCM participants have, albeit unintentionally, assumed a level of authority and status that can be alienating to others.

Finally, though not a criticism of the core tenets of the theory itself, because of the relative age of the SCM, there is a scarcity of available empirical research that assesses its lasting impact on leadership development (Haber \& Komives, 2009). The SCM served as the basis of Dugan and Komives's (2007) Multi-Institutional Study of Leadership, which provides important quantitative data about students' perceptions of leadership on the scale of the SCM's values. The study also suggests that there is significant potential for helping students develop leadership competencies (Dugan \& Komives, 2007). Additionally, Dugan's (2006) work provides important insight into the role of involvement measures using the SCM, but there remain significant opportunities for future research on the applicability and lasting impact of the model.

\section{A New Conceptual Model}

Outside of the limitations discussed here and suggestions regarding a lack of empirical support for his propositions, the Tinto model has been fundamental to changing how institutions think about student persistence and retention, and it provides a theoretical underpinning to numerous academic and social support programs on college campuses (Braxton, Milem, \& Sullivan, 2000; Braxton, Sullivan, \& Johnson, 1997). Moreover, even with ongoing debate about its specific components, the primary tenets of Tinto's input - environment - output model have gained wide acceptance in higher education (Braxton, et al., 1997; Kuh, et al., 2006). Accordingly, I propose the Improving Persistence through Social Change Leadership (IPSCL) integrated conceptual 
framework that largely keeps intact Tinto's explanations that students arrive at college with certain ascribed and achieved characteristics, that they are challenged and shaped by their new collegiate environments, that academic and social integration are important to their feelings of success, and that decisions to persist or not can be informed by a combination of all of these factors.

This IPSCL model diverges from the Tinto model because of the infusion of pertinent elements of the SCM, which have been brought in to address the components of the Tinto model that have deconstructed in this paper. The illustrated model found at the conclusion of this paper presents the basic outline of the IPSCL, which contains four main components: (1) a precollege context (input) dimension, (2) an institutional commitment dimension, (3) an institutional and community environment dimension, and (4) a resultant experience (output) dimension. Each of these components explains important elements of input, environment, and output, and there is interplay between the dimensions showing a reciprocal effect.

The SCM has been specifically incorporated into both the institutional commitment and institutional and community environment dimensions of the IPSCL model. The institutional commitment dimension shows components of an integrated leadership training program rooted in the SCM for all incoming students. This program is meant to reflect the principles of the SCM, and as departments and divisions from academic affairs, student affairs, and senior administration all participate in its construction and fulfillment, it also signals recognition by the institution that a multilayered response to the persistence issue is needed. This component of the new model directly addresses the lack of an institutional action plan in the original Tinto (1975) model. The SCM is introduced particularly because its unique dimensions and its foundational emphasis on change for the common good, offer opportunities for new ways for institutions to think about and approach persistence.

In the institutional and community environment dimension of the IPSCL model are a multitude of traits, all reflective of the SCM, including common good, sense of belonging, equity, empowerment, and collaboration. The incorporation of these elements of the SCM into the institutional commitment and institutional and community environment dimensions is also meant to intersect with and challenge Tinto's (1987) revision regarding the expectation that students separate from their precollege identities and assimilate into the dominant institutional and normative values. Tinto (1975) correctly suggested that precollege family and other ascribed attributes are important predictors of student persistence, and while this dimension is important to shaping a student's perceptions, the structure of this new framework intends to articulate an approach in which components like family background and individual attributes are seen as assets that will be included in determining each student's path to academic and social integration. By incorporating institution-wide participation in leadership programs rooted in the SCM, these precollege contextual elements shift from being challenges to persistence and retention to qualities used by students to redefine their college experiences. Rather than adopting new norms, students utilize their ascribed and 
achieved characteristics to create new meaning for what Tinto (1975) described as collegiate integration.

Finally, the resultant experience (output) dimension presents an outline of the ultimate effects of the model. These effects illustrate how, ideally, the IPSCL model benefits the student participants, the community, and persistence rates. As a result of the inclusion of the students' ascribed and achieved precollege characteristics from the input dimension, the institutional commitment to a SCM leadership program in the second dimension, and impact from the enhanced community environment in the third dimension, by the resultant experience dimension, students are meant to have gained enhanced confidence and beliefs in their own abilities (efficacy), along with greater capacities, an enhanced sense of identity development, and improved resilience, of which the latter two play a role in the socially responsible nature of their leadership behaviors (Dugan, 2006). The IPSCL model is structured so that meaningful participation in each of the dimensions is meant to guide students to gain academic and social integration in the community, and to become the kind of "engaged owners of their community" described by Heifetz (2010). With the combination of the assumed validity of relevant components of the Tinto model and the hoped outcomes of active, participatory citizenship from the SCM, these factors will have the effect of improved rates of student persistence.

The IPSCL model also directly addresses the absence of social-psychological elements from the Tinto model. For example, the new framework is designed to counteract stereotype threat and social comparison by using participation in leadership programs as a means to generate inclusivity and to encourage students to take ownership in meaning making. As students gain a sense of agency and confidence through leadership training, the model's structure is intended to motivate them to construct their own experiences and to push back against what were the previously held normative institutional expectations. Especially for underrepresented students in this process, as they confront stereotyped perceptions and challenge others to consider their own hidden biases, this framework is meant to provide space for student leaders to gain efficacy and begin redefining the notion of developed leader (Hoyt \& Murphy, 2016).

While far fewer, the elements of the SCM deconstructed here are intended to be addressed by the relative placement of those elements and the ways in which they are incorporated into the IPSCL framework. In other words, any existing limitations with the SCM are addressed by where the SCM is included with the idea that the other elements of the model will give further definition to those shortcomings. For example, the concept of citizenship is the primary focus of my deconstruction of the SCM. To address this, I have infused the element of citizenship into both the institutional commitment and institutional and community environment dimensions of the IPSCL as a way to better define it and provide perspective to what it means in context and in relationship to the other components. As the illustrated model demonstrates, citizenship in this context is connected to the idea of multiple memberships and to the expectation that citizens in the community establish relationships with those influenced by decisions. This is meant to create a framework for reciprocal empowerment (Laycock, 2011). 
In this framework, notions of what it means to integrate into the community are flexible and are meant to be defined by student participants. This is unlike the Tinto model in which the conditions of integration into the community are dictated to students by the institution's existing norms and values. In the IPSCL model, existing communities retain their forms of capital and students acquire agency as a result of being engaged in an institution-wide commitment to the SCM. In consideration of this element, it is fair to assess this new framework as highly individualistic, and this is intentional. This element also makes the model reflective of the kind of collective, constructionist leadership explored by Ospina and Su (2009) in which leadership is described as being fluid and in which ascribed characteristics like race and ethnicity are interwoven as a way to encourage people to define leadership.

The IPSCL integrated conceptual framework is designed both to enhance theoretical understanding and to contribute to educational practices related to undergraduate student persistence. I attempt to show how this framework can help users to better understand the important relationship between leadership theory based on creating positive change and a benchmark model of student retention. This new framework also clearly articulates the integration of relevant elements from both the SCM and Tinto persistence models as well as the reciprocal relationship that exists between both models. This framework has applicability for analyzing new approaches to student persistence and retention, and also as a source for the creation of new models. 

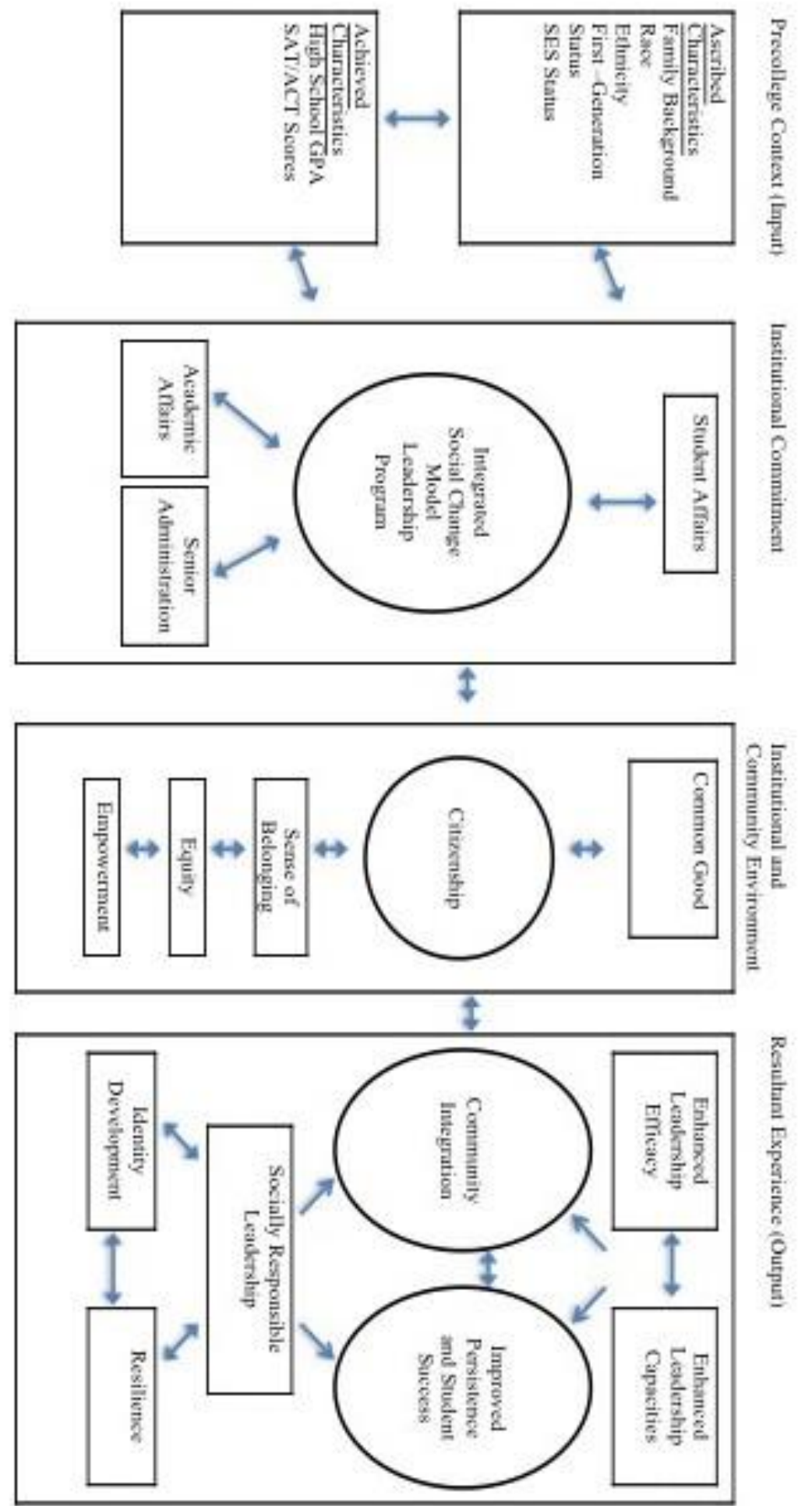

IPSCL Improving Persistence through Social Change Leadership 


\section{Discussion}

There are numerous connections between leadership and undergraduate student persistence and retention. However, as I attempted to demonstrate through this model, it is important that we move away from the traditional, normalized, romanticized notions of a single transformational leader, especially as those notions relate to whiteness (Liu \& Baker, 2014; Robinson, Hohepa, \& Lloyd, 2007). The backgrounds, perspectives, and unique contextual elements derived from the ascribed and achieved characteristics of incoming college students need to be meaningfully woven into redefining the concept of integration. In exploring "mestizo consciousness," Anzaldua (2010) suggests that the contradictions in mixed cultures represent an incredible richness, and that misperceptions need to change. Those with mixed culture identifications can have unique perspectives and ways of challenging traditional thinking that make their inclusion extremely valuable, especially to the change process (Anzaldua, 2010). The focus that the IPSCL model places on the meaningful inclusion of the perspectives inherent from diverse ascribed characteristics represents a significant challenge to the original Tinto persistence model. Through participation in leadership training grounded in the SCM, students are provided with a structure by which their precollege contexts are given an important voice.

There is a multileveled purpose to the IPSCL model. First, it is meant to disrupt the assumptions made by Tinto about who undergraduate students are, the necessity of students to conform to existing normative institutional values, and what they must do to thrive. In outlining an approach in which students gain agency and become leaders invested in and in control of their own outcomes via social change, the new framework challenges Tinto's student-institution fit assumptions. Tinto's notions of the importance of academic and social integration remain intact, but instead of placing the obligation on students to disassociate from their precollege environments and characteristics in an effort to gain acceptance by the dominant culture, the IPSCL encourages them to become leaders and collaborate to create their own communal values, allowing them to define their own conceptualizations of social integration.

The most important goal of the IPSCL framework is to offer a nuanced and complex understanding of the interaction between social change leadership and student persistence. Referring back to the Wolniak, et al., (2012) work, distinct connections exist between socially responsible leadership and persistence, especially since, as the authors suggest, persistence may be viewed by students as an important component to positive leadership. Considering the particular relevance of persistence solutions to underrepresented populations, the IPSCL model has the potential to enhance the study of leadership theory and to impact practices that implicate relevant issues of equity and social justice. As for the theoretical component, by blending the academic and social integration elements of the Tinto model with relevant elements of the SCM, a roadmap for conceptualizing how the infusion of leadership theory into a persistence model is offered, which can be important to how leadership theory is explained in literature and taught. Perhaps more significantly, in application, models such as the IPSCL offer the 
possibility to spur productive resistance and positive disruption to traditional leadership paradigms.

\section{Implications for Future Research}

The IPSCL is intended to address many of the shortcomings of the Tinto model and to offer a potential path for how leadership theory, practically applied, can be useful in improving rates of persistence. Since a majority of students who do not persist in their undergraduate studies to degree completion are underrepresented by race, ethnicity, and first-generation and socioeconomic status (Kinzie, Gonyea, Shoup, \& Kuh, 2008; Museus, 2014), there are obvious social justice implications if the use of integrated models such as the IPSCL were to begin making a difference in persistence rates. Despite the model's intentions in this manner, understanding more about how it and others like it may be relevant and applicable to students from diverse populations represents an important line of future inquiry. The IPSCL is a framework that must be tested, and until research is conducted that assesses the model's validity for diverse students, any conclusions about its relevance and usefulness for different groups would be premature.

Additionally, I believe that successful implementation of the IPSCL model offers opportunities for positive disruptions to current leadership structures. The emphasis the model places on the role of students from diverse backgrounds has the potential to push college administrators to not simply count the numbers of enrolled students from diverse backgrounds, but instead to invest in inclusive and meaningful leadership practices (Gallegos, 2014). If institutions can move beyond mere acceptance or tolerance of diverse perspectives and toward a model that encourages the incorporation of these perspectives, there is greater potential for changes to institutional cultures (Gallegos, 2014). Of course, only time, the thoughtful and purposeful implementation of models like this at different institution types, and the process of empirical academic research will demonstrate the likelihood of achieving these objectives.

Finally, it is important for scholars to explore how other models of student persistence could be integrated with the SCM and other leadership theories. Persistence models including Museus's (2014) culturally engaging campus environments (CECE) model; Milem and Berger's (1997) model related to student behavior, perceptions, and integration; and Braxton, Hirschy, and McClendon's (2004) model implicating the concept of psychosocial engagement have each made a meaningful contribution to how student persistence is perceived, understood, and addressed, and examining how these and other models can intersect and integrate with different leadership frameworks offers important possibilities. 


\section{References}

Alvesson, M., \& Spicer, A. (2014). Critical perspectives on leadership. The Oxford Handbook of Leadership and Organizations, 40.

Anzaldúa, G. (1997). La conciencia de la mestiza: Towards a new consciousness. Chicana feminist thought: The basic historical writings, 270-274.

Bean, J. P. (1982). Conceptual models of student attrition: How theory can help the institutional researcher. In New directions for institutional research, (36), 17-33.

Bennett, C., \& Okinaka, A. M. (1990). Factors related to persistence among Asian, Black, Hispanic, and White undergraduates at a predominantly White university: Comparison between first and fourth year cohorts. The Urban Review, 22(1), 3360 .

Berger, J. B., \& Braxton, J. M. (1998). Revising Tinto's interactionalist theory of student departure through theory elaboration: Examining the role of organizational attributes in the persistence process. Research in Higher Education, 39(2), 103119.

Berger, J. B., \& Lyon, S. C. (2005). Past to present: A historical look at retention. In A. Seidman (Ed.), College student retention: Formula for student success (pp. 1-30). Westport, CT: Praeger Publishers.

Berger, J. B., \& Malaney, G. D. (2003). Assessing the transition of transfer students from community colleges to a university. NASPA journal, 40(4), 1-23.

Born, W.K., Revelle, W. \& Pinto, L.H. (2002). Improving biology performance with workshop groups. Journal of Science Education and Technology, 11(4), 347-365.

Braxton, J.M., Hirschy, A.S., \& McClendon, S.A. (2004). Understanding and reducing college student departure. ASHE-ERIC Higher Education Report, Vol. 30, No. 3. Washington, D.C.: School of Education and Human Development, The George Washington University.

Braxton, J. M., Milem, J. F., \& Sullivan, A. S. (2000). The influence of active learning on the college student departure process: Toward a revision of Tinto's theory. Journal of Higher Education, 569-590.

Braxton, J. M., Shaw Sullivan, A. V., \& Johnson, R.M (1997). Appraising Tinto's theory of college student departure. Higher education: Handbook of theory and research, $12,107-158$. 
Burnette, J. L., Pollack, J. M., \& Hoyt, C. L. (2010). Individual differences in implicit theories of leadership ability and self-efficacy: Predicting responses to stereotype threat. Journal of Leadership Studies, 3(4), 46-56.

Cilente, K. (2009). An overview of the social change model of leadership development. In S.R. Komives, W. Wagner, \& Associates (Eds.), Leadership for a better world: Understanding the social change model of leadership development (43-78). San Francisco, CA: Jossey-Bass.

Donatelli, S.N. (2010). Help-seeking attitudes and intentions among first generation college students. (Unpublished doctoral dissertation). Purdue University, West Lafayette, Indiana.

Dugan, J. P. (2006). Explorations using the social change model: Leadership development among college men and women. Journal of College Student Development, 47(2), 217-225.

Dugan, J.P. (2017). Leadership theory: Cultivating critical perspectives. San Francisco, CA: Jossey-Bass.

Dugan, J. P., Kodama, C., Correia, B., \& Associates. (2013). Multi-Institutional Study of leadership insight report: Leadership program delivery. College Park, MD: National Clearinghouse for Leadership Programs.

Dugan, J. P., \& Komives, S. R. (2007). Developing leadership capacity in college students: Findings from a national study. A report from the Multi-Institutional Study of Leadership. College Park, MD: National Clearinghouse for Leadership Programs.

Elkins, S. A., Braxton, J. M., \& James, G. W. (2000). Tinto's separation stage and its influence on first-semester college student persistence. Research in Higher Education, 41(2), 251-268.

Engle, J. (2007). Postsecondary access and success for first-generation college students. American Academic, 3(1), 25-48.

Engle, J., Bermeo, A., \& O'Brien, C. (2006). Straight from the source: What works for first-generation college students. Pell Institute for the Study of Opportunity in Higher Education.

Enns, C. Z. E., \& Sinacore, A. L. (2005). Teaching and social justice: Integrating multicultural and feminist theories in the classroom. Washington, D.C.: American Psychological Association.

Gallegos, P. V. (2014). The work of inclusive leadership. Diversity at work: the practice of inclusion, 177-202. 
Haber, P., \& Komives, S. R. (2009). Predicting the individual values of the social change model of leadership development: The role of college students' leadership and involvement experiences. Journal of Leadership Education, 7(3), 133-166.

Heifetz, R. (2010). Leadership. In R.A. Couto (Ed.), Political and civic leadership: A reference handbook (pp. 12-23). Thousand Oaks, CA: Sage.

Higher Education Research Institute. (1996). A social change model of leadership development: Guidebook version III. College Park, MD: National Clearinghouse for Leadership Programs.

Housel, T. H., \& Harvey, V. L. (2009). The invisibility factor: Administrators and faculty Reach out to first-generation college students. Boca Raton, FL: Brown Walker Press.

Hoyt, C. L., \& Murphy, S. E. (2016). Managing to clear the air: Stereotype threat, women, and leadership. The Leadership Quarterly, 27(3), 387-399.

Humphreys, M. J. (2011). A new generation of leaders for Eastern Europe: Values and attitudes for active citizenship. Christian Higher Education, 10(3-4), 215-236.

Kenny, M. E., and Stryker, S. (1996). Social network characteristics and college adjustment among racially and ethnically diverse first-year students. Journal of College Student Development, 37(6): 649-658.

Kezar, A. (2010). Leadership for a better world: Understanding the social change model of leadership development (review). The Journal of Higher Education, 81(5), 670-671.

Kinzie, J., Gonyea, R., Shoup, R., \& Kuh, G. D. (2008). Promoting persistence and success of underrepresented students: Lessons for teaching and learning. New Directions for Teaching and Learning, 2008(115), 21-38.

Komives, S. R., \& Wagner, W. (2012). Leadership for a better world: Understanding the social change model of leadership development. San Francisco, CA: John Wiley \& Sons.

Kuh, G. D., Kinzie, J., Buckley, J. A., Bridges, B. K., \& Hayek, J. C. (2006). What matters to student success: A review of the literature. In Commissioned report for the National Symposium on Postsecondary Student Success: Spearheading a dialog on student success.

Laanan, F. S. (2001). Transfer student adjustment. New Directions for Community Colleges, 2001(114), 5-13. 
Laycock, D. (2011). Representation and democratic theory. Vancouver, Canada: UBC Press.

Liu, H. Baker C (2014) White Knights: Leadership as the heroicisation of whiteness. Leadership, 1-29.

Metz, G. W. (2004). Challenge and changes to Tinto's persistence theory: A historical review. Journal of College Student Retention: Research, Theory \& Practice, 6(2), 191-207.

Micari, M. \& Drane, D. (2011). Intimidation in small learning groups: The roles of social comparison concern, comfort, and individual characteristics in student academic outcomes. Active Learning in Higher Education, 12(3), 175-187.

Milem, J. F., \& Berger, J. B. (1997). A modified model of college student persistence: Exploring the relationship between Astin's theory of involvement and Tinto's theory of student departure. Journal of College Student Development, 38(4), 387.

Museus, S. D. (2014). The culturally engaging campus environments (CECE) model: A new theory of success among racially diverse college student populations. In Higher education: Handbook of theory and research (pp. 189-227). Springer

Netherlands.

Ospina, S., \& Su, C. (2009). Weaving color lines: Race, ethnicity, and the work of leadership in social change organizations. Leadership, 5(2), 131-170.

Owen, J.E. (2012). Findings from the Multi-Institutional Study of Leadership Institutional Survey: A National Report. College Park, MD: National Clearinghouse for Leadership Programs.

Richardson, R.C. \& Skinner, E.F. (1992). Helping first generation minority students achieve degrees. In L.S. Zwerling \& H.B. London (Eds.), First generation college students: Confronting the cultural issues (pp. 29-44). San Francisco, CA: JosseyBass Publishers.

Robinson, V. M., Hohepa, M., \& Lloyd, C. (2007). School leadership and student outcomes: Identifying what works and why (Vol. 41). Melbourne: Australian Council for Educational Leaders.

Smedley, B. D., Myers, H. F., \& Harrell, S. P. (1993). Minority-status stresses and the college adjustment of ethnic minority freshmen. Journal of Higher Education, 434-452.

Swail, W. S. (2004). The art of student retention: A handbook for practitioners and administrators. Austin, TX: Educational Policy Institute. 
Terenzini, P., Springer, L., Yaeger, P., Pascarella, E., \& Nora, A. (1996). First-generation college students: Characteristics, experiences, and cognitive development. Research in Higher Education, 37, 1-22.

Thornberry, T. P. (1989). Reflections on the advantages and disadvantages of theoretical integration. In S. F. Messner, M. D. Krohn, and A. E. Liska (eds.), Theoretical integration in the study of deviance and crime (pp. 51-60). Albany, NY: State University of New York Press.

Tierney, W. G. (1992a). An anthropological analysis of student participation in college. Journal of Higher Education, 63(6), 603-618.

Tierney, W. G. (1992b). Official encouragement, institutional discouragement: Minorities in academe--the Native American experience. Interpretive perspectives on education and policy [Series]. Greenwich, CT: Ablex Publishing Corp.

Tinto, V. (1975). Dropouts from higher education: A theoretical synthesis of recent literature. A Review of Educational Research, 45, 89-125.

Tinto, V. (1987). Leaving college: Rethinking the causes and cures of student attrition. Chicago: The University of Chicago.

Tinto, V. (1988). Stages of student departure: Reflections on the longitudinal character of student leaving. The Journal of Higher Education, 59(4), 438-455.

Tinto, V. (1993). Leaving college: Rethinking the causes and cures of student attrition. (2nd ed.). Chicago, IL: University of Chicago Press.

Tinto, V. (1999). Taking retention seriously: Rethinking the first year of college. NACADA Journal, 19(2), 5-9.

Tinto, V. (2000). Linking learning and leaving: Exploring the role of the college classroom in student departure. In J. M. Braxton (Ed.), Reworking the student departure puzzle (pp. 81-94). Nashville, TN: Vanderbilt University Press.

Tinto, V. (2004). Student retention and graduation: Facing the truth, living with the consequences. Washington, D.C.: The Pell Institute.

Tinto, V. (2007). Research and practice of student retention: What next? Journal of College Student Retention: Research, Theory \& Practice, 8(1), 1-19.

Tyree, T. M. (1998). Designing an instrument to measure socially responsible leadership using the social change model of leadership development (Unpublished doctoral dissertation). University of Maryland, College Park. 
Wagner, W. (1996). The social change model of leadership: A brief overview.

Leadership, 11.

Wolniak, G. C., Mayhew, M. J., \& Engberg, M. E. (2012). Learning's weak link to persistence. The Journal of Higher Education, 83(6), 795-823.

\section{Author Biography}

Andrew French is a Ph.D. student in Higher Education at Loyola University Chicago. Andrew's research interests include the relationship between teaching and student academic success, including the role of mindset in faculty members' approach to teaching and in their perceptions of their students. Andrew can be reached at afrench5@luc.edu. 